\title{
Modernização urbana e educação das sensibilidades na cidade de Vitória (1890-1912)*
}

\author{
Urban modernization and the education of the \\ sensibilities in the city of Vitória (1890-1912)
}

\begin{abstract}
Arnaldo Pinto Junior
Professor adjunto da Universidade Federal do Espírito Santo (UFES), bacharel em História pela Unicamp e doutor em Educação pela mesma universidade apjbrasil@hotmail.com
\end{abstract}

\section{Resumo:}

Este trabalho apresenta reflexões acerca do processo de modernização na cidade de Vitória, entre os anos de 1890 e 1912. Ao analisar projetos urbanísticos e discursos defendidos pelos grupos dominantes locais, procuro evidenciar as batalhas de percepçóes ocorridas em um cenário marcado por transformaçóes do viver urbano, que também (re)significaram a história e a memória coletiva. Compreendendo esse processo como manifestaçáo do avanço das concepçóes da modernidade capitalista no Espírito Santo, problematizo as perspectivas socioculturais que hierarquizaram conhecimentos em detrimento de memórias plurais.

Palavras-chave: História cultural; Modernidade; Educação das sensibilidades

\section{Abstract:}

This paper presents some insights about the modernization process in the city of Vitória between 1890 and 1912. By analyzing urbanistic projects and speeches supported by the local dominant groups, I aim at demonstrating the battles of perceptions which took place in an environment surrounded by transformations in the urban life, which also (re)signified the collective history and memory. While understanding this process as the manifestation of the advance of the conceptions of the capitalist modernity in the State of Espírito Santo, I problematize the socio-cultural perspectives that hierarchized knowledge in spite of plural memories.

Keywords: Cultural history; Modernity; Education of the sensibilities

* Trabalho apresentado no GT Memória e Educação das Sensibilidades 


\section{Artigos \& Ensaios}

Orestas pesquisadores que focalizam as cidades na contemporaneidade traba lham com a complexidade de sua história, espacialidade, economia, sociedade e dos sentidos culturais relacionados ao seu contínuo desenvolvimento. A acelerada expansão dos centros urbanos, sobretudo observada a partir de meados do século XIX, está associada ao processo de avanço da modernidade capitalista. Primeiramente nos países industrializados do hemisfério Norte, posteriormente nas mais diferentes regióes do planeta, o fenômeno da urbanização produziu marcas significativas nos últimos 150 anos.

Os discursos modernos concorreram de forma efetiva para a constituição de ideais de vivências urbanas, os quais apontaram para os indeléveis signos de civilidade, racionalidade, prosperidade, produtividade, segurança, saúde, dentre outros. Segundo os referidos discursos, as relaçôes sociais nas cidades garantiriam as condiçôes essenciais de vida ao homem moderno, sujeito afeito às temporalidades urbanas, seduzido pelas novas tecnologias e comodidades oferecidas apenas nos locais onde o atraso deixara de existir.

Entretanto, se hoje as novas geraçóes dialogam com o referido ideário sem apresentar grandes questionamentos, as múltiplas referências culturais dos sujeitos que viveram as transformaçóes nos séculos XIX e XX produziram, ao mesmo tempo, encantamentos e estranhamentos, aproximaçóes e distanciamentos, dominações e resistências. $\mathrm{O}$ adensamento populacional das metrópoles, os novos ritmos de vida, a perda de referências sociais, o desenraizamento dos sujeitos e exacerbação do individualismo geraram sensibilidades conflitantes (SENNETT, 1998: 261-265).

Para os homens engajados na tarefa de difundir as concepçóes da modernidade, inúmeros desafios deveriam ser ultrapassados: como legitimar as regras do mercado de trabalho urbano em um cenário dominado por práticas culturais do espaço rural? Como incluir os sujeitos considerados à margem do ideal de civilização? Como estabelecer paradigmas da cultura letrada em uma sociedade majoritariamente analfabeta? Como educar as sensibilidades das novas geraçóes no sentido de valorização dos símbolos da modernidade? Como conquistar os coraçóes e mentes dos sujeitos hierarquicamente desqualificados pela ordem capitalista? Como adequar os espaços urbanos ao progresso capitalista? Como reformar as caóticas cidades construídas no passado?

Refletindo sobre os projetos socioculturais defendidos pelos sujeitos modernos no decorrer do século XIX e nas primeiras décadas do século XX, temos a convicção de que as demandas não eram simples de serem solucionadas. $\mathrm{O}$ objetivo era contornar todos os empecilhos que pudessem impedir a concretização do progresso e, para se alcançar o estágio idealizado pelos preceitos civilizatórios, deveriam ser abarcadas questóes legais, administrativas, educacionais, econômicas, urbanísticas, enfim, concepçóes socioculturais mais amplas.

Devido à abrangência dos aspectos envolvidos, as visóes relativas à modernidade foram instituídas gradativamente, com avanços e retrocessos, em um processo dialético de relações de forças sociais e de (re)produção de conhecimentos.

É com este objetivo que encontramos as elites sociais do Espírito Santo no final dos oitocentos, ou seja, buscando a transformaçáo da capital do estado, Vitória, em uma cidade moderna, capaz de representar à altura a importância de seu povo e de sua economia. Ao aproximar-se dos ideais da modernidade brasileira, as elites espírito-santenses dialogaram com modelos estabelecidos pelos padróes culturais ocidentais, trabalhando no sentido de valorizar o estado e, 
principalmente, a sua capital, representação do progresso local.

Como em todos os exemplos de avanço da modernidade nos mais variados países, as contradiçóes que envolveram o processo no Espírito Santo provocaram tensôes entre as visóes de passado, presente e futuro, entre a história desejada e as memórias coletivas, entre os sujeitos modernos e os sujeitos rotulados como atrasados.

\section{A EDUCAÇÁo das SENSIBILIDAdeS E A CULTURA NA MODERNIDADE}

$\mathrm{O}$ debate referente à modernidade no mundo contemporâneo contribuiu para instigantes reflexóes, mas nem sempre essas contribuiçốes são evocadas em novas análises. Invariavelmente nos deparamos com comparaçóes realizadas entre diferentes cidades - de países com suas respectivas especificidades - tomando-se como base os signos modernos construídos desde o século XIX. Ao desconsiderar as contradiçóes existentes nos centros urbanos atualmente enaltecidos como exemplos a serem seguidos, ao buscar a homogeneização de distintas culturas e vivências urbanas, ao ignorar a historicidade de cada urbe e populaçáo, as superficiais comparaçóes hierarquizam sujeitos e conhecimentos.

Esclarecendo o conceito de modernidade capitalista, fundamental para esta pesquisa, dialogamos com as contribuições do filósofo Walter Benjamin, as quais articulam os processos culturais modernos - experiências, sensibilidades e visóes de mundo - ao avanço das relaçóes capitalistas de produção. Autor de estudos que analisaram as perspectivas culturais construídas pelas sociedades capitalistas após a revolução industrial, Benjamin afirma que:

$\mathrm{O}$ século $[\mathrm{XIX]}$ não soube corresponder às novas virtualidades técnicas com uma nova ordem social. É por isso que a última palavra coube às mediaçóes enganosas do antigo e do novo, que estáo no coração de suas fantasmagorias. O mundo dominado por essas fantasmagorias é - para usarmos a expressão encontrada por Baudelaire - a Modernidade (Benjamin, 2009: 67).

Segundo a historiadora Maria Carolina Bovério Galzerani, não existe nos estudos de Benjamin uma visão definitiva e/ou estrutural do conceito de modernidade capitalista. Para Galzerani, o pensador berlinense concebe:

(...) o conceito de modernidade intimamente articulado ao avanço do sistema capitalista. Seu olhar metodológico permite-lhe ampliar a concepção de sistema capitalista - pensando em inúmeras elaboraçóes analíticas construídas na relação com o marxismo -, uma vez que incluiu, no interior do conceito de relaçôes sociais de produção, a dimensão cultural, as visões de mundo e de sensibilidades. E, na recuperação deste movimento dialético, encara a cultura ao mesmo tempo como produto e produtora das relaçóes sociais. Permite, pois, que focalizemos as sensibilidades náo como naturais ou psicologicamente compreensíveis, mas enquanto construçôes historicamente dadas (GALZERANI, 2002: 53-54). 
Compreendemos que a metodologia benjaminiana, ao problematizar determinados desdobramentos do sistema capitalista, potencializa as análises relativas aos processos históricos, ressaltando os movimentos dialéticos das produçóes culturais, bem como as experiências, visões de mundo e sensibilidades humanas.

Nessa perspectiva, acreditamos que as obras do historiador Peter Gay (1988, 1999) também contribuem metodologicamente para a ampliação de nossas reflexóes acerca da modernidade. Trabalhando com uma diversidade de práticas culturais, na Europa e na América do Norte durante o século XIX e as primeiras décadas do século XX, o referido pesquisador concebe-as inseridas historicamente na trama das relaçóes sociais burguesas, as quais apresentaram movimentos de dominação e resistência. Ao sublinhar o difuso, mas incisivo processo de educação das sensibilidades, do qual as práticas culturais fazem parte, Gay reforça a ideia de construção coletiva dos conhecimentos. Na análise da educação das sensibilidades no período recortado, fundamentando-se na História marxista cultural e também na psicanálise, o pesquisador promove uma ampliação da própria dimensáo de ser sujeito, bem como do conceito de cultura, uma vez que os considera abarcados tanto pela dimensão consciente, como pelo inconsciente. O conceito de cultura é apresentado em sua obra a partir da ideia de movimento contínuo, difuso e contraditório, de produção de visóes de mundo e formas de sociabilidades e sensibilidades.

Com estes referenciais teórico-metodológicos, entendemos que a difusão das concepçóes de modernidade pelo mundo é mais um dos desdobramentos observados no avanço do sistema capitalista, principalmente após meados do século XIX, com a denominada Revolução Científico-Tecnológica (SEVCENKO, 1998: 8). Alicerçados na valorização das ciências, da produção de riqueza acumulativa, do contínuo progresso, da educação institucionalizada, da cultura letrada, da racionalidade técnica-instrumental, da hierarquização dos saberes, dentre outros aspectos, os discursos proferidos pelos triunfantes defensores da modernidade conquistaram, gradativamente, a aceitação e o apoio de diversas classes sociais, principalmente os integrantes das elites liberais intelectualizadas.

Acreditando que os estudos científicos potencializariam a frenética busca pelo progresso e apontando a educaçáo como estimuladora de um processo civilizatório eficiente, os sujeitos modernos instituíram uma educação das sensibilidades que reforçou a esperança no futuro promissor, contrapondo-se ao passado menos glorioso, ou mesmo repleto de dificuldades vividas pela humanidade. Construindo hipotéticas sociedades organizadas, disciplinadas, pacíficas e justas, os discursos modernos projetavam a superação dos problemas que afligiam o mundo até aquele momento.

A esperança de prosperidade material e cultural conquistou coraçóes e mentes a partir do século XIX, não por acaso denominado o "século das ciências". Os discursos progressistas da modernidade associavam as pesquisas científicas e os avanços técnicos aos povos civilizados, detentores do conhecimento humano mais sofisticado. Somente os povos tecnicamente avançados poderiam desfrutar dos benefícios trazidos pela modernidade: novas drogas para o combate de enfermidades, meios de comunicação mais confiáveis, meios de transportes mais rápidos, habitações mais confortáveis e adequadas aos novos padróes de higiene, cidades projetadas para facilitar o fluxo de pessoas e mercadorias, espaços urbanos capazes de manter o desenvolvimento econômico e de disciplinar a vida social de seus habitantes. 
Enquanto esses discursos não eram excludentes, sob o ponto de vista social, em sua origem liberal, as práticas cotidianas relacionadas ao capitalismo marginalizavam aqueles que não tinham condições de pagar pelos novos serviços e mercadorias disponibilizadas aos consumidores. Efetivamente, o ideal de povo que incluía todos os sujeitos estava restrito ao discurso. $\mathrm{O}$ cidadão moderno foi partido, as condiçóes econômicas impulsionaram a divisão entre aqueles que poderiam pagar pelas novidades científicas e os avanços tecnológicos e aqueles que não teriam acesso "às maravilhas do mundo moderno".

Em diversos países, os processos de urbanização das grandes e médias cidades não promoveram à maioria de seus habitantes, acessos ao saneamento básico, aos meios de transporte, à educação escolar, à assistência médica, às condições dignas de moradia, situaçóes que acentuaram os problemas relacionados ao viver urbano.

Atendendo prioritariamente os grupos mais abastados da sociedade e, consequentemente, as áreas onde esses sujeitos habitavam e/ou atuavam, os projetos de modernizaçáo das cidades foram vivenciados em variadas condiçóes pelas populaçóes urbanas na virada do século XIX para o XX.

Dessa forma, a Revolução Científico-Tecnológica que potencializou o avanço do sistema capitalista, acabou contribuindo para o significativo aumento de práticas culturais excludentes. Pensando nos esperançosos discursos modernos, que em determinados aspectos apaziguavam as tensóes sociais e minimizavam as diferenças entre sujeitos de classes distintas, o avanço do capitalismo consolidou a hierarquização sociocultural nas cidades.

No Brasil, observamos que algumas expansóes urbanas tiveram início na segunda metade do século XIX. Capitais de províncias - como São Paulo, Porto Alegre, Salvador e Recife - e principalmente, a capital do país, já esboçavam um processo de metropolização neste período. A exemplo do que ocorreu em cidades norte-americanas e europeias, o processo de metropolização no Brasil intensificou a separação das classes sociais, sobretudo a partir da especulação imobiliária, fenômeno que valorizou espaços privilegiados do centro urbano, devidamente resguardado para as elites locais. Em cidades mais populosas do interior e outras capitais do país, o crescimento das áreas urbanas também seguia a mesma lógica das cidades que se transformavam em metrópoles. Trabalhadores marginalizados pelos processos de reurbanização e/ou expansão urbana no período, acabaram convivendo com problemas sérios de habitação, educação, saneamento, saúde pública e violência.

Seguindo os paradigmas da urbanização em países considerados mais avançados economicamente, discursos liberais brasileiros defenderam a expansão urbana como um ícone do desenvolvimento nacional, processo capaz de desencadear a diversificação da produção de riqueza em um país agroexportador. Transformar o Brasil em um país urbanizado era um projeto praticamente inalcançável para a sociedade rural do Império. Sonho distante sim, mas os progressistas brasileiros tinham a esperança de conquistar o status de naçáo civilizada. Urbanização, industrialização, educação, civilização, termos citados recorrentemente pelos liberais que defendiam as concepçóes da modernidade capitalista. As elites nacionais, encantadas com a modernização dos centros urbanos na Europa e nos Estados Unidos, desejavam reestruturar as ultrapassadas cidades brasileiras, mesmo que para isso a maioria da população ficasse à margem do processo de melhoramentos (PINTO JR, 2003). 


\section{UMA NOVA CAPITAL PRODUZINDO NOVOS HOMENS}

Debater o moderno na América Latina é debater a cidade: a cidade americana náo é apenas o produto mais genuíno da modernidade ocidental, mas também, ademais, é um produto criado como uma máquina para inventar a modernidade, estendê-la e reproduzi-la. Assim foi concebida durante a Colônia, primeiro, para situar os enclaves a partir dos quais produzir o território de modo moderno; nas repúblicas independentes, depois, para imaginar nesses territórios as naçóes e os Estados à imagem e semelhança da cidade e de sua cidadania; nos processos de desenvolvimento, faz táo pouco tempo, para usá-la como "polo" a partir do qual se expandir a modernidade, restituindo o contínuo rural-urbano segundo seus parâmetros, isto é, dirigidos para produzir homens social, cultural e politicamente modernos (GORELIK, 1999: 55).

Nas palavras de Adrián Gorelik, a invenção da modernidade na América Latina está relacionada ao espaço urbano. Centro das decisóes políticas, as cidades irradiaram sua cultura, seja no período colonial ou pós-independência. No caso de Vitória, as imagens de uma cidade sedutora, polo de produção cultural e referência de desenvolvimento econômico não surgem com facilidade até o final do período monárquico.

As transformações urbanísticas mais acentuadas foram verificadas após a proclamação da República, em 1889. Segundo setores das elites republicanas que governaram o estado a partir deste ano, a capital espírito-santense não poderia continuar apresentando os sinais de um passado indesejável, de uma cidade pouco produtiva para os padróes modernos, modos de vida marcadamente provincianos, muito distantes das visóes culturais que conquistavam cada vez mais adeptos em outras regióes do país.

A coincidência da efetiva modernização capixaba com o período republicano está relacionada aos governos estaduais empenhados no planejamento e execução desses projetos. As administraçôes dos presidentes do Espírito Santo, José de Mello Carvalho Muniz Freire (em dois mandatos não consecutivos, de 1892 a 1896 e 1900 a 1904) e Jerônimo de Souza Monteiro (1908-1912), são apontadas por pesquisadores como as responsáveis pelo referido processo.

Segundo o historiador Gilton Luis Ferreira, "o primeiro governante ousou no planejamento da cidade, o segundo foi responsável pela realização das diversas obras idealizadas anteriormente, dando continuidade ao processo de expansão pensado para Vitória ao término dos Oitocentos" (FERREIRA, 2009: 113).

No relatório administrativo do Presidente de estado, referente ao seu primeiro mandato, Muniz Freire explicita os problemas da capital, herdados do passado, apontando a possibilidade para a superação dos mesmos:

Vitória, cidade velha de aspecto colonial, pessimamente construída, sem alinhamento, sem esgoto, sem arquitetura, se guindo os caprichos do território, apertada entre 
a baía e um grupo de montanhas, não tem campo para desenvolver-se sem a dependência de grandes despesas. Enᄀtretanto, possui um porto em condiçóes admiráveis, indiscutivelmente muito supe $\neg$ rior a todos os outros do Estado e um dos melhores do Brasil. (Freire, 1896: 17)

As percepções registradas no relatório de governo também deveriam circular na capital do estado antes mesmo da implantação do regime republicano. Quando afirmamos que diversos projetos de modernizaçáo foram incentivados a partir da República, não estamos descartando a existência dos mesmos no período monárquico. A historiadora Maria Stella Martins Bresciani (1976, 1982) problematiza em suas pesquisas visóes historiográficas unidimensionais, portadoras de tendências deterministas. Contrapondo-se às produçóes mecanicistas na área, Bresciani trabalha com uma concepção de ideologia liberal como componente institutivo do social e não, simplesmente, desdobramento de um determinado processo. Ao analisar os discursos liberais entre o final do Império e início da República, Bresciani evidencia as convergências e/ou dissonâncias das correntes socioculturais em ação, apontando para a multiplicidade de vozes e projetos, destacando-se as perspectivas positivistas, românticas e católicas, as quais foram amalgamadas e fundamentaram o avanço das concepçóes de modernidade no Brasil.

As valiosas contribuiçôes metodológicas apresentadas por Bresciani reafirmam a complexidade do processo histórico que envolveu a modernização de Vitória. Os referencias da modernização urbana não nasceram com o regime republicano, muito menos eram ideias originais do movimento republicano brasileiro. Na Europa, os processos de urbanização em Londres, Paris, Madrid e Roma tiveram grande impulso com regimes monárquicos. Por outro lado, as cidades norte-americanas que passaram por grandes transformaçóes urbanísticas eram governadas por elites republicanas.

O diferencial, no caso do relato do presidente de estado Muniz Freire, é a expressão do poder público, que reconhece uma série de problemas advindos da velha estrutura urbana. A presença do ideário moderno entre as classes dominantes no período é indiscutível, pois o antigo deve ser substituído pelo novo.

A expansão urbana de Vitória, que se desenvolveu junto ao acanhado porto desde o período colonial, não contemplava as novas demandas econômicas e socioculturais. Ruas irregulares e estreitas, que cortavam os reduzidos espaços existentes entre os aterros, os morros e o mar, confluíam para o pequeno cais de madeira, incapaz de receber grandes embarcaçóes. $\mathrm{O}$ confuso trânsito de carroças e animais de transporte impedia a disciplinada e produtiva circulação de mercadorias e pessoas. Além disso, epidemias assolavam uma população desprovida de saneamento básico. Enfim, a cidade precisava superar os entraves constatados pelas autoridades para desenvolver seu potencial econômico e gerar melhores condiçôes de vida à população.

Se a estrutura urbana da capital do estado era desalentadora até o fim do século XIX, interpretando o relato do presidente Muniz Freire, o porto poderia impulsionar as transformaçóes idealizadas pelos preceitos das sociedades civilizadas. Apresentando "condiçóes admiráveis", o projeto de reestruturação do porto acabou balizando a modernização e expansão urbana de Vitória.

Para a historiadora Maria da Penha Smarzaro Siqueira (2010), as obras na 
região portuária tiveram um papel significativo nas intervençóes urbanas empreendidas pelos poderes públicos, pois o porto representou o agente principal para o progresso de todo o Espírito Santo, além de pautar outros projetos de modernização da capital.

Siqueira analisa as transformações urbanísticas de Vitória, destacando os fundamentos do sistema capitalista e a difusão de valores burgueses que perpassavam por tal processo:

Nessa perspectiva, estruturou-se um plano de reformulação urbana em três dimensões; as obras de estruturaçáo e o aparelhamento do porto, o saneamento da cidade e a reforma urbana, aspectos que marcaram o perfil socio $\neg$ espacial da cidade, dinamizado pelo comércio do café que direcionava as relaçóes cidade-porto (SIQUEIRA, 2010: 572).

As três dimensóes enumeradas reafirmam os princípios do capitalismo nas ações dos poderes públicos espírito-santenses: estimular a produção e circulação de riquezas, ampliando os equipamentos urbanos para que estes pudessem potencializar a economia de mercado. Paralelamente, a modernizaçáo urbanística legitimaria as açóes empreendidas porque proporcionaria aos moradores de Vitória condiçôes de vida semelhantes aos das metrópoles mais desenvolvidas. A educação das sensibilidades ocorria através de desejos idealizados e expectativas de progresso contínuo, difundindo-se a crença na infalível evolução técnico-científica. Mais do que viver os benefícios do avanço da modernidade, buscou-se moldar formas de sociabilidades e sensibilidades, instituindo-se a busca incessante do novo em contraposiçáo ao velho, seja no âmbito da mercadoria, seja no campo do conhecimento.

Apontados como os principais responsáveis pela reurbanização de Vitória, Muniz Freire e Jerônimo Monteiro eram representantes das forças políticas dominantes no estado, as quais estavam procurando estabelecer articulaçóes socioculturais mais amplas, identificadas com as concepçóes da modernidade capitalista, ideário defendido por diversos setores das elites brasileiras.

Para representar melhor as transformaçóes que as modernas elites do estado pretendiam realizar, a cidade de Vitória deveria passar por um processo de urbanização semelhante às grandes metrópoles mundiais. Sem dúvida, os sujeitos modernos do Espírito Santo estavam maravilhados com os projetos urbanísticos de Paris, Londres e Nova Iorque, pela monumentalidade de edifícios, avenidas e praças, pelos variados estilos arquitetônicos, pelos encantadores equipamentos viários. Mas a capital do Brasil possuía particularidades mais cativantes, pois existiriam certas similaridades entre o Rio de Janeiro e Vitória. Além da proximidade geográfica, os discursos das elites locais destacavam as significativas semelhanças: a ocupação litorânea, o clima, o relevo acidentado, as generosas belezas naturais, uma baía com águas tranquilas que favoreciam o comércio portuário, a posiçáo estratégica no estado, enfim, tudo indicava que não existia melhor modelo a ser seguido.

Maior ícone da modernização urbana brasileira desde o início do século XIX, a capital do Brasil constituiu-se em paradigma emblemático para o desenvolvimento sociocultural de inúmeras cidades brasileiras (SEVCENKO, 1998). Os governantes do regime político implantado em 1889 realizaram diversos 
projetos de modernização pelo país. No que se refere às questôes urbanísticas, tanto os homens modernos que viviam nas cidades mais populosas como os que viviam em cidades menos desenvolvidas do país buscaram adequar seu espaço aos novos padróes.

Se compararmos as transformaçóes higienizadora, urbanística, viária, educacional e arquitetônica de outras capitais do país, notadamente as mais populosas e politicamente mais articuladas, com os poderes do regime republicano - como eram São Paulo, Porto Alegre, Recife, Salvador - a capital do Espírito Santo náo teve um volume de recursos financeiros investidos na mesma proporção, não podendo apresentar aos moradores e visitantes, obras tão monumentais e impactantes como nas referidas cidades.

A ausência de recursos mais vultosos não impediu que as transformações realizadas na capital do Espírito Santo servissem para o propósito das intervenções do estado: instituir um cenário urbano condizente ao ideário da modernidade. Junto com as novas paisagens arquitetônicas e urbanísticas da cidade, o projeto modernizador acabou renegando determinados aspectos do passado colonial, sobretudo os que faziam referência à cultura popular. Qual o valor dos conhecimentos de camponeses ou de pescadores diante dos avanços técnicos e científicos trazidos do estrangeiro? Como as memórias coletivas, transmitidas pela oralidade, podem ser mais importantes que a história política, registrada nos livros?

O processo de modernizaçáo de Vitória na virada do século XIX para o século XX pode ser comparado ao do Rio de Janeiro em diversos pontos: na execução de aterros que ampliaram a área útil da ilha, na construção de avenidas próximas ao mar, na expansão do porto e no atendimento privilegiado às classes dominantes. Fenômeno que se repetiu, respeitando-se as devidas proporçóes nas mais diversas cidades, a urbanização regeneradora (SEVCENKO, 1999) foi contraditória, pois se por uma lado afastava os sujeitos indesejáveis e/ou considerados incapazes de habitar as áreas civilizadas, por outro atraia para as suas cercanias os responsáveis pelo trabalho doméstico diário, pelo transporte de mercadorias, pela construção civil e demais serviços braçais.

As elites que toleravam a "proximidade produtiva" dos sujeitos desqualificados pela ordem moderna - trabalhando nas casas, ruas, praças e outros logradouros -, eram as mesmas que procuravam relegar ao esquecimento as memórias coletivas que remetiam ao passado colonial. A história oficial desejada e difundida por setores elitizados da sociedade espírito-santense não conseguiu destruir as memórias sociais que guardavam as referências de um passado pouco edificante para os sujeitos modernos. Tampouco as tensões entre as versôes históricas construídas pelas elites letradas e as memórias coletivas acabaram com o avanço das concepçóes relativas à modernidade no Espírito Santo.

Por mais que os projetos de modernização em Vitória tenham sido elaborados para concretizaçáo de projetos econômicos e atendimento de grupos específicos da sociedade local, os sentidos ambivalentes desse processo tornaram o cenário urbano um espaço pleno de conflitos e possibilidades (BERMAN, 1997: 21). Entre prédios públicos, belas residências, praças aprazíveis e novas vias de trânsito, circulavam sujeitos modernos e trabalhadores urbanos, cada qual com suas expectativas e visóes de mundo. A cidade moderna - centro administrativo, local de comércio, lazer e moradia - potencializou o sistema capitalista, conciliando prosperidade econômica, bem-estar e maior visibilidade aos sujeitos detentores 
dos poderes. Contraditoriamente, a cidade moderna foi frequentada, cotidianamente, por trabalhadores que movimentavam casas, meios de transporte, repartiçôes, armazéns do porto, sujeitos marginalizados na ordem capitalista, portadores de memórias e histórias dissonantes, que circularam entre os mais seletos grupos, dialogando com a cultura letrada, mas evidenciando as batalhas de percepçóes (GAY, 1988) constituídas nos cenários urbanos da contemporaneidade.

\section{REFERÊNCIAS BIBLIOGRÁFICAS}

BENJAMIN, Walter. Passagens. Belo Horizonte: Editora UFMG; São Paulo: Imprensa Oficial do Estado de São Paulo, 2009.

BERMAN, Marshall. Tudo Que é Sólido Desmancha no Ar: A Aventura da Modernidade. São Paulo: Companhia das Letras, 1997.

BRESCIANI, Maria Stella Martins. "Liberalismo: ideologia e controle social (um estudo sobre São Paulo de 1850 a 1910).” 1976. 2 v. Tese (Doutorado em História Social). Faculdade de Filosofia, Letras e Ciências Humanas, Universidade de São Paulo, São Paulo, 1976.

. Londres e Paris no Século XIX: o Espetáculo da Pobreza. São Paulo: Brasiliense, 1982. (Coleção Tudo é história, v. 52)

CERTEAU, Michel de. A Invenção do Cotidiano: 1. Artes de Fazer. 15ª ed. Petrópolis, RJ: Vozes, 2008.

FERREIRA, Gilton Luis. "Um desejo chamado metrópole: a modernização da cidade de Vitória no limiar do século XX”. 2009. 175 f. Dissertação (Mestrado em História). Centro de Ciências Humanas e Naturais, Universidade Federal do Espírito Santo, Vitória, 2009.

FREIRE, José de Melo Carvalho Muniz. Relatório do Presidente do Estado do Espirito Santo (1892-1896). Victoria: Typographia Nelson Costa \& Companhia, 1896.

GALZERANI, Maria Carolina Bovério. "O almanaque, a locomotiva da cidade moderna: Campinas, décadas de 1870 e 1880”. 1998. 341 f. Tese (Doutorado em História). Instituto de Filosofia e Ciências Humanas, Universidade Estadual de Campinas, Campinas, 1998.

"Imagens entrecruzadas de infância e de produção de conhecimento em Walter Benjamin”. In: FARIA, Ana Lúcia Goulart de; DEMARTINI, Zeila de Brito Fabri; PRADO, Patrícia Dias (org.). Por Uma Cultura de Infância: Metodologias de Pesquisa com Crianças. Campinas, SP: Autores Associados, 2002. (Coleção educação contemporânea)

GAY, Peter. A Experiência Burguesa da Rainha Vitória a Freud: a Educação dos Sentidos. São Paulo: Companhia das Letras, 1988.

- O Coração Desvelado: a Experiência Burguesa da Rainha Vitória a Freud. São Paulo: Companhia das Letras, 1999.

GORELIK, Adrián. "O moderno em debate: cidade, modernidade e modernização”. In: MIRANDA, Wander Melo (org.). Narrativas da Modernidade. Belo Horizonte: Autêntica, 1999.

PINTO JR, Arnaldo. A invenção da "Manchester Paulista": embates culturais em Sorocaba (1903-1914). 2003. 234 f. Dissertação (Mestrado em Educação). Faculdade de Educação, Universidade Estadual de Campinas, Campinas, 2003.

SENNETT, Richard. O Declinio do Homem Público: as Tiranias da Intimidade. São Paulo: Companhia das Letras, 1998. 
SEVCENKO, Nicolau. Literatura Como Missão: Tensóes Sociais e Criação Cultural na Primeira República. 1a reimpr. da 4a ed. São Paulo: Brasiliense, 1999.

SEVCENKO, Nicolau (Org.). História da Vida Privada no Brasil: da Belle Époque à Era do Rádio. São Paulo: Companhia das Letras, 1998, v. 3.

SIQUEIRA, Maria da Penha Smarzaro. "A cidade de Vitória e o porto nos princípios modernos da urbanização no início do século XX”. In: Cadernos Metrópole. São Paulo: v. 12, n. 24, p. 565-584, jul/dez 2010.

THOMPSON, Edward Palmer. Costumes em Comum. São Paulo: Companhia das Letras, 1998. 